\title{
Accessibility and Integration Study of Part of the Abu Dhabi 2030 Master Plan by Using Space Syntax
}

\author{
Rim Meziani \\ Architecture and Design Department, Abu Dhabi University, Abu Dhabi, United Arab Emirates
}

\begin{abstract}
This paper studies the accessibility of open spaces and facilities and the integration of streets to the whole urban system of the Emirati neighbourhood of the Business District of the Abu Dhabi 2030 Master Plan. For this purpose, axial lines were produced by applying space syntax theory, Depthmap software. The research aims to verify the location of open spaces and facilities, such as schools, in relation to the location of public transportation stops (bus, metro and tram), in order to check their accessibility within walking distances. The objective is to pay attention to the relationship between land use and transportation in the planning phase for future interventions or proposals, in other words, to improve the accessibility of public spaces or buildings by pedestrians in order to comply with the vision of the Abu Dhabi 2030 Master Plan and its promotion of walkability and cycling. Although many measures will be taken at the scale of urban design to provide shaded open spaces and sidewalks, saving pedestrians from walking long distances shall be done in the planning phase, the challenge remains to create a micro climate to increase the ease of walking in the heat and decrease dependence on cars for mobility.
\end{abstract}

Key words: Abu Dhabi 2030 Master Plan, accessibility, space syntax.

\section{Introduction}

The Abu Dhabi 2030 Master Plan was completed in 2007 by the Abu Dhabi Urban Planning Council. Its vision is to create a sustainable lifestyle in the new capital city that will reflect the image of this international city and modern capital. This modernity in a sustainable environment would not be possible without highlighting local identity and preserving traditional and cultural values. Hence, planning for future urban development shall be based on the above criteria. In this context, designs for the Emirati neighborhood not only refer to the traditional architecture and shading and cooling techniques, but also represent the low-rise residential component of the Master Plan with its open spaces and facilities.

Space syntax approach considers the city as a spatial network. It has been used as a method and theory of space in research and design $[1,2]$. It has

Corresponding author: Rim Meziani, Ph.D., associate professor, research fields: urban studies, GIS, space syntax, visualization, and spatial analysis. been successfully applied to analyze the dynamism of a city, to study indoor and outdoor movement and circulation [1], accessibility and visibility, etc. hence the author chose to apply space syntax in this research. Specifically using axial lines and segment analysis by axial lines and segment analysis by Depthmap software. Furthermore, the possibility to analyze the integration [3, 4] of a small component of a given system into the whole and then compare it with other components is one of the considerable achievements that Depthmap and space syntax in general have brought to the field, and this contributed to the author choosing this software in her research $[5,6]$.

From this perspective, the author developed an interest to study the accessibility to open spaces and parks, at the scale of the neighborhood by using space syntax in order to assess their location within a walking distance, and the degree of usage and benefit of these spaces by the community. Finally, we believe that the results of this study could be beneficial to the community. 


\section{Presentation of the Study Area}

\subsection{Abu Dhabi City}

The city of Abu Dhabi was established in the middle of the 18th century as a focal point for the pearl trade and hunting. Later with the discovery of oil, it has grown economically. In 1971, it became the federal capital of the UAE after the Union of the seven Emirates: Abu Dhabi, Dubai, Fujairah, Ras al-Khaimah, Sharjah, and Umm al-Quwain [7] (Fig. 1). Today Abu Dhabi has a population of nearly one million [8].

The continued economic development, the rapid population growth, the liberalization of the real estate laws, the large foreign investment and numerous construction projects have all influenced the birth of the Abu Dhabi 2030 Master Plan, which was designed and implemented in 2007 by the Abu Dhabi UPC
(Urban Planning Council) [8].

\subsection{Abu Dhabi Master Plan 2030}

The objective of the urban structure framework plan proposed in the 2030 Master Plan was to create Abu Dhabi as an "urban capital" with an expected population of 2 million in 2020 and 3.1 million in 2030. The target is also to attract 4.9 million tourists annually by 2020 and 7.9 million annually by 2030 [8]; these are extremely ambitious objectives.

The Capital District itself, which has an area of $45 \mathrm{~km}^{2}$ of land, is planned to accommodate more than 350,000 residents and to attract a daytime population of 810,000 to which 100,000 jobs will be provided, which underlines the importance of the Capital District in the development of the Abu Dhabi of the future (Fig. 2) [8].

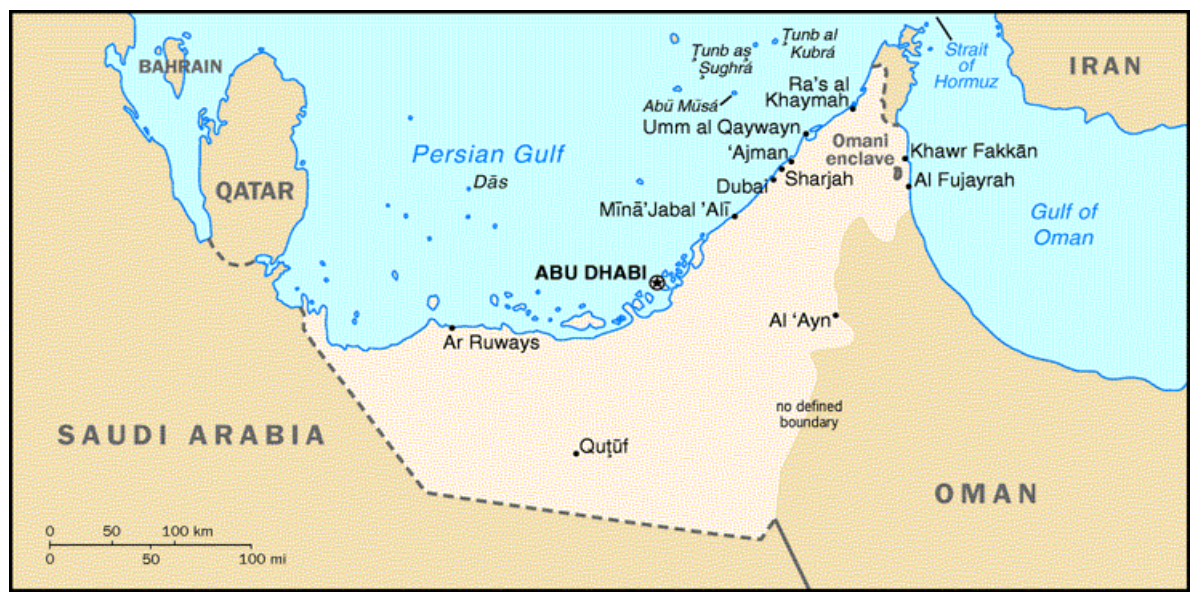

Fig. 1 Location map of Abu Dhabi city in the United Arab Emirates.

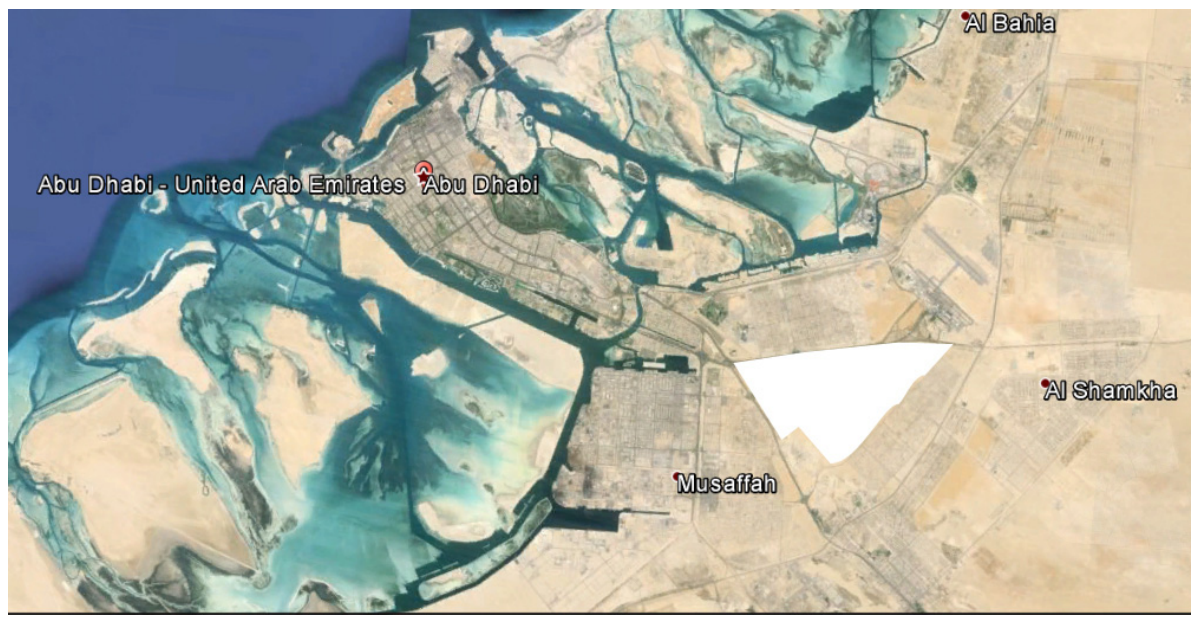

Fig. 2 Location of the 2030 Master plan area. 
Six major precincts make up the Capital District: Federal Precinct, City Center Precinct (CBD (central business district)), Souk District, North Spine District, Federal Mosque District, Emirati Neighborhood, Sport Hub Precinct, South Spine Precinct and Palace Precinct (Fig. 3). Their land use distribution, locations, transport infrastructure, density, urban form and open space were decided in accordance with the whole system [9].

A variety of land use and building rise are included in the six precincts. In some parts, low-rise buildings are predominant with universities, research centers, mosques, and community neighborhoods with all the necessary facilities, sports, conference venues, and embassy neighborhoods (Fig. 4).

In other parts, high-rise buildings such as commercial offices, the national government house and buildings are aligned along the main streets to emphasize the visual axes to the CBD. The street network design and the urban design were planned in order to end with two plazas, one big and one small that are to be surrounded with landmarks, monuments and government buildings to give more importance to the Federal Precinct not only at the metropolitan level, but also at the national (Fig. 5).

The Capital District is well connected to the rest of the city through a good transportation network such as highways, trams and metro networks. The vision of Abu Dhabi 2030 promotes the use of public transportation and encourages walkability and cycling. However, this seems perhaps a little over optimistic due to the hard climate, e.g., the average maximum temperatures reach above $50{ }^{\circ} \mathrm{C}\left(122{ }^{\circ} \mathrm{F}\right)$ on the coastal plain during the hottest months of in summer (July and August) [10].

Hence, the interest of this research is to study the accessibility of the open spaces, as examples of public spaces within walking distance of the residential area located in the Emirati neighborhood. Accessibility on foot to these spaces, if provided under comfortable circumstances, would considerably enhance the physical and psychological health of people and promote socialization among the inhabitants of the same neighborhood.

\section{Methodology}

The author decided to work on a small scale to analyze the integration and accessibility of minor and

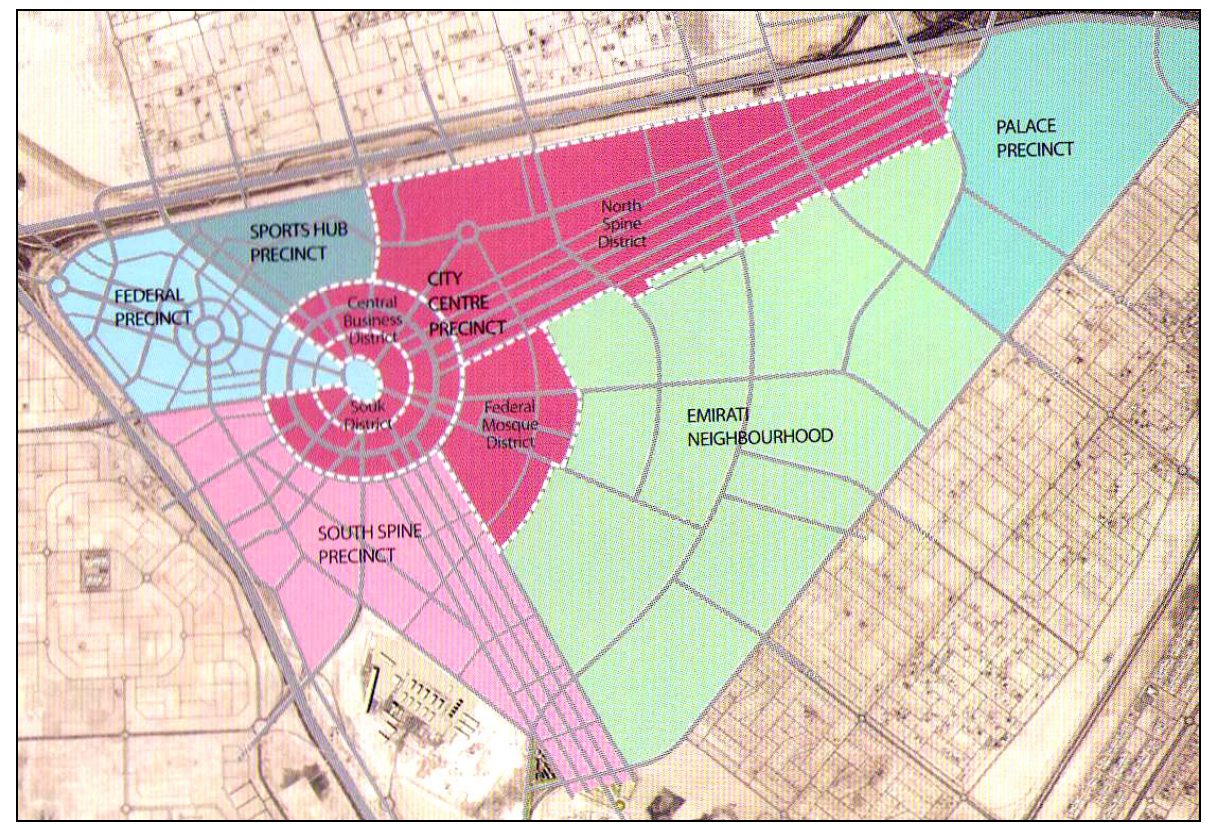

Fig. 3 The six major precincts of the Capital District.

Source: The Abu Dhabi Urban Planning Council. 


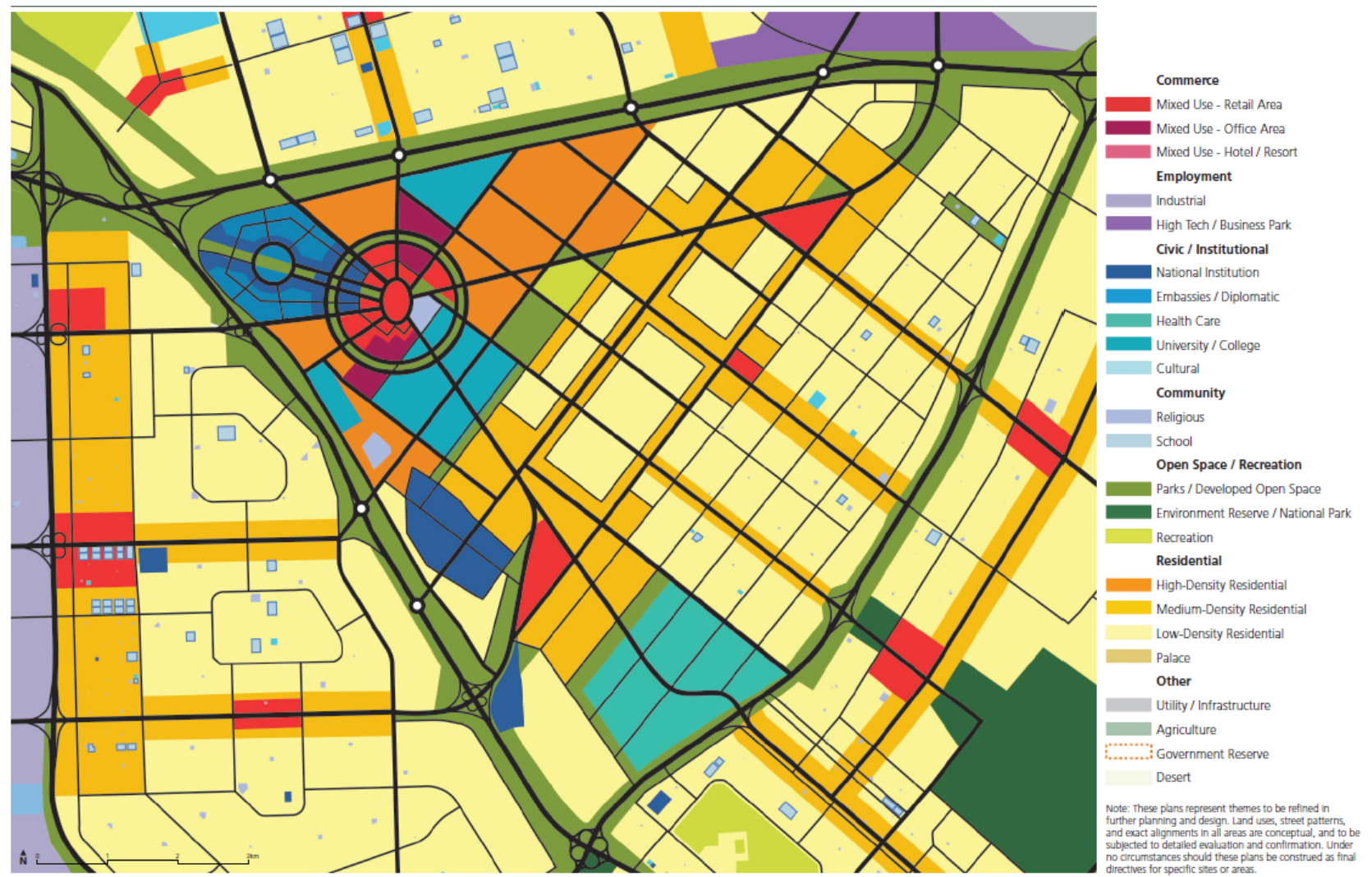

Fig. 4 Land use map of the Capital District Abu Dhabi Master Plan 2030.

Source: The Abu Dhabi Urban Planning Council, 2007.

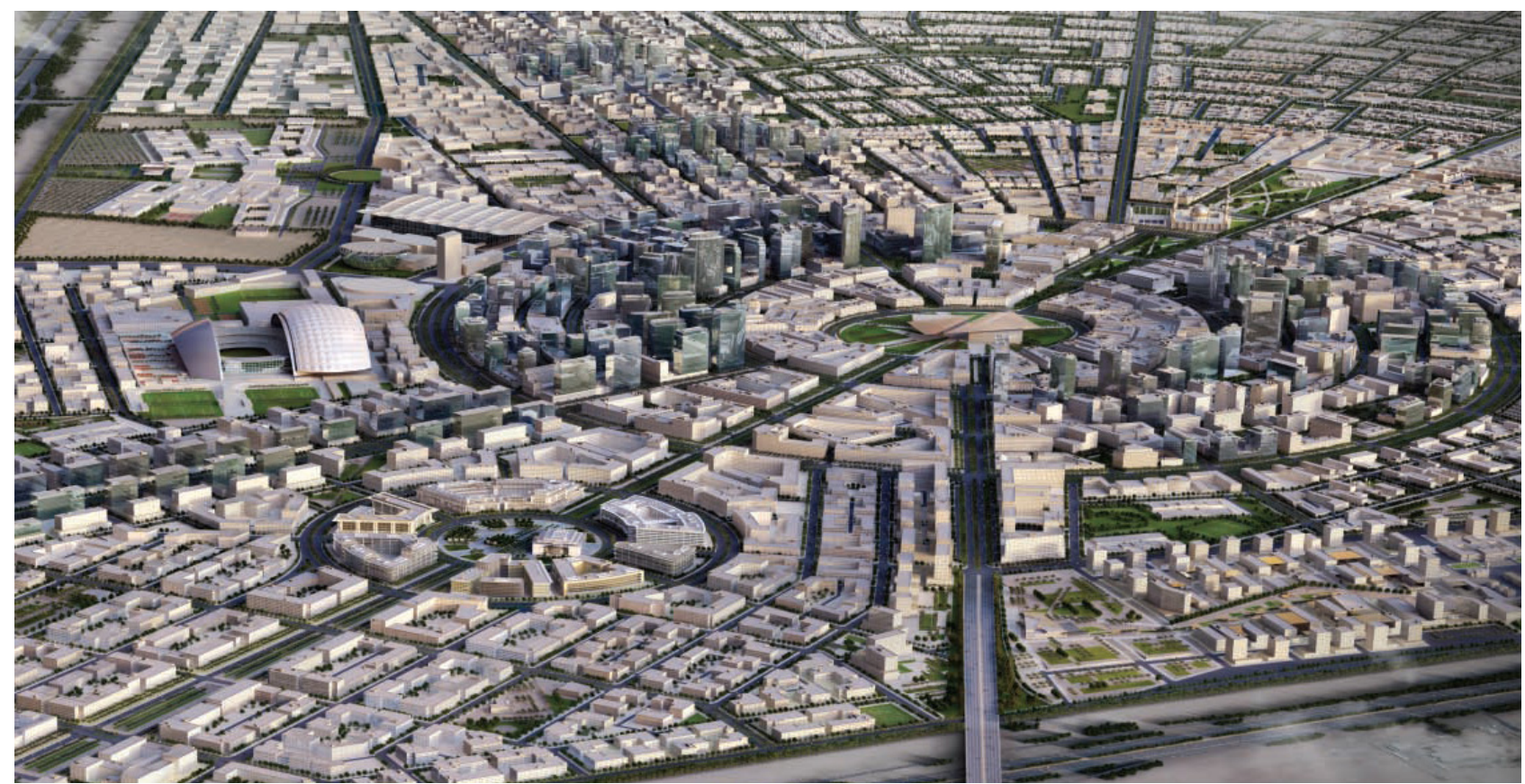

Fig. 5 The 3D model of the main square in the Capital District.

Source: The Abu Dhabi Urban Planning Council, 2007.

local roads and compare them to the whole system, which means that the focus was to conduct a segment analysis of the streets. For this purpose, an axial line graph was firstly produced by using Depthmap 
software for the whole capital district area emphasizing its streets network (Fig. 6).

Secondly, a segment graph was generated from the axial graph. Thirdly, visibility analysis related to connectivity, integration, total depth, choice, and node count [11] was carried out on the segment graph [12]. Here we are interested more in the integration measure, since it is known to be the most consistent measure for correlation with pedestrian movement [4].

Fourthly, segment analysis was carried out by using the metric type of radius. The radii were chosen according to the following walking distances: $400 \mathrm{~m}$, $800 \mathrm{~m}, 1,200 \mathrm{~m}$ which represent approximately $5 \mathrm{~min}$, $10 \mathrm{~min}$ and 15 min walking time (Figs. 7-9).

The next step was to analyze the graphs and compare them with the land use map in Fig. 5 and the street hierarchy map in Fig. 10 and the walking and cycling roads map in Fig. 11, where circles of 5 min walking distance from tram and metro stops are represented.

The objective of this comparison is to identify any segment of the street network, or part of the urban structure which is not well integrated to the whole system, which would indicate less accessibility. This includes open and closed spaces.

The comparison is also meant to verify if the location of the public transportation stops including bus, tram and metro, and the location of the public buildings, facilities, land marks, parks, etc., as proposed in the 2030 Master Plan, are sufficient to provide good accessibility for pedestrians within an optimum and comfortable walking time to reach their destinations, especially in the hot climate of the UAE.

\section{Results Analysis, Findings and Considerations}

We are presenting the total depth values of the segments in order to show "the cumulative total of the shortest angular path to the segments", which is the meaning of the total angular depth as explained by Turner $[5,6]$. The different values are categorized in groups from low to high and represented by default in the graph by different colors. The blue represents the lowest value, and the red represents the highest value.

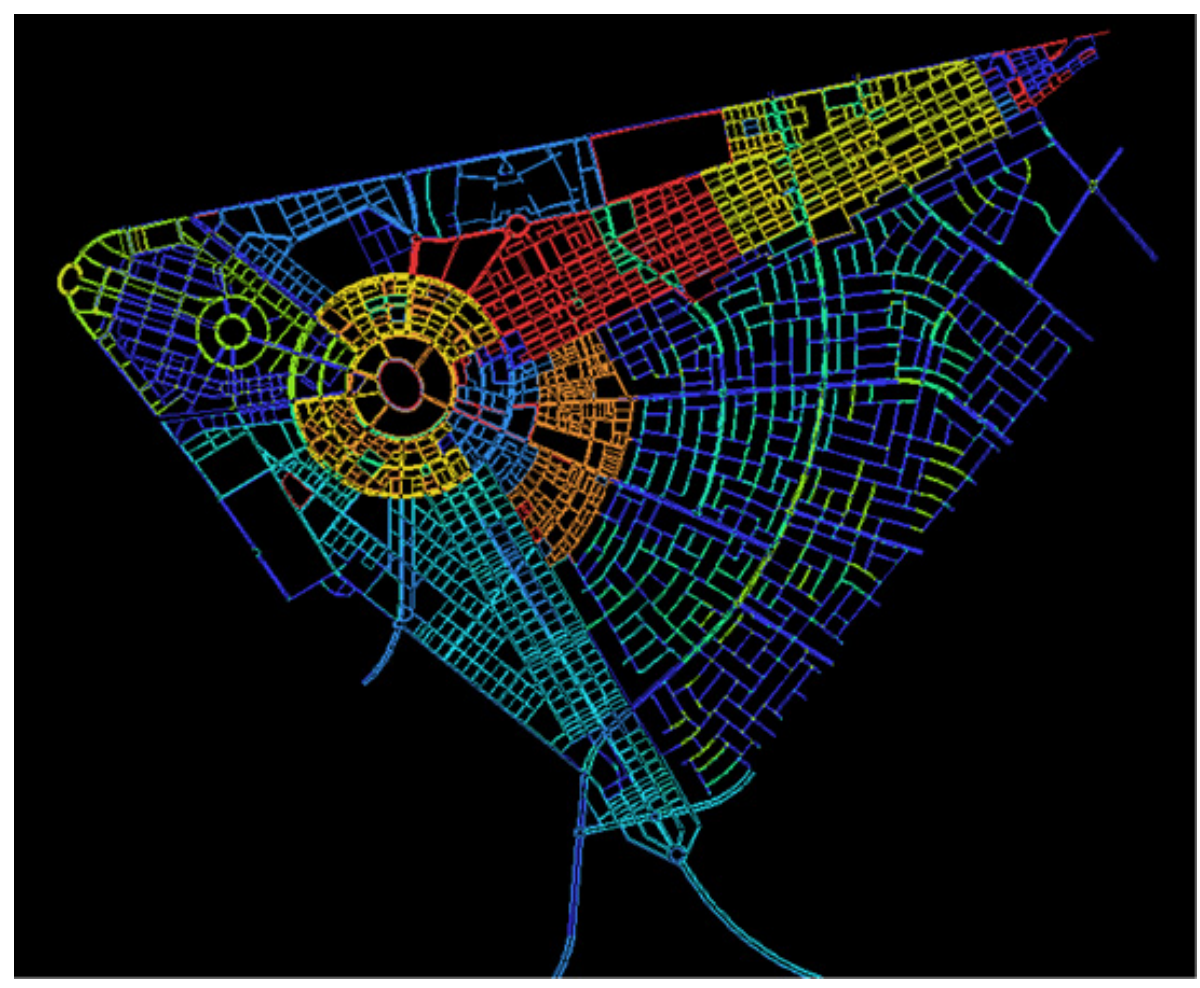

Fig. 6 Axial lines references. 


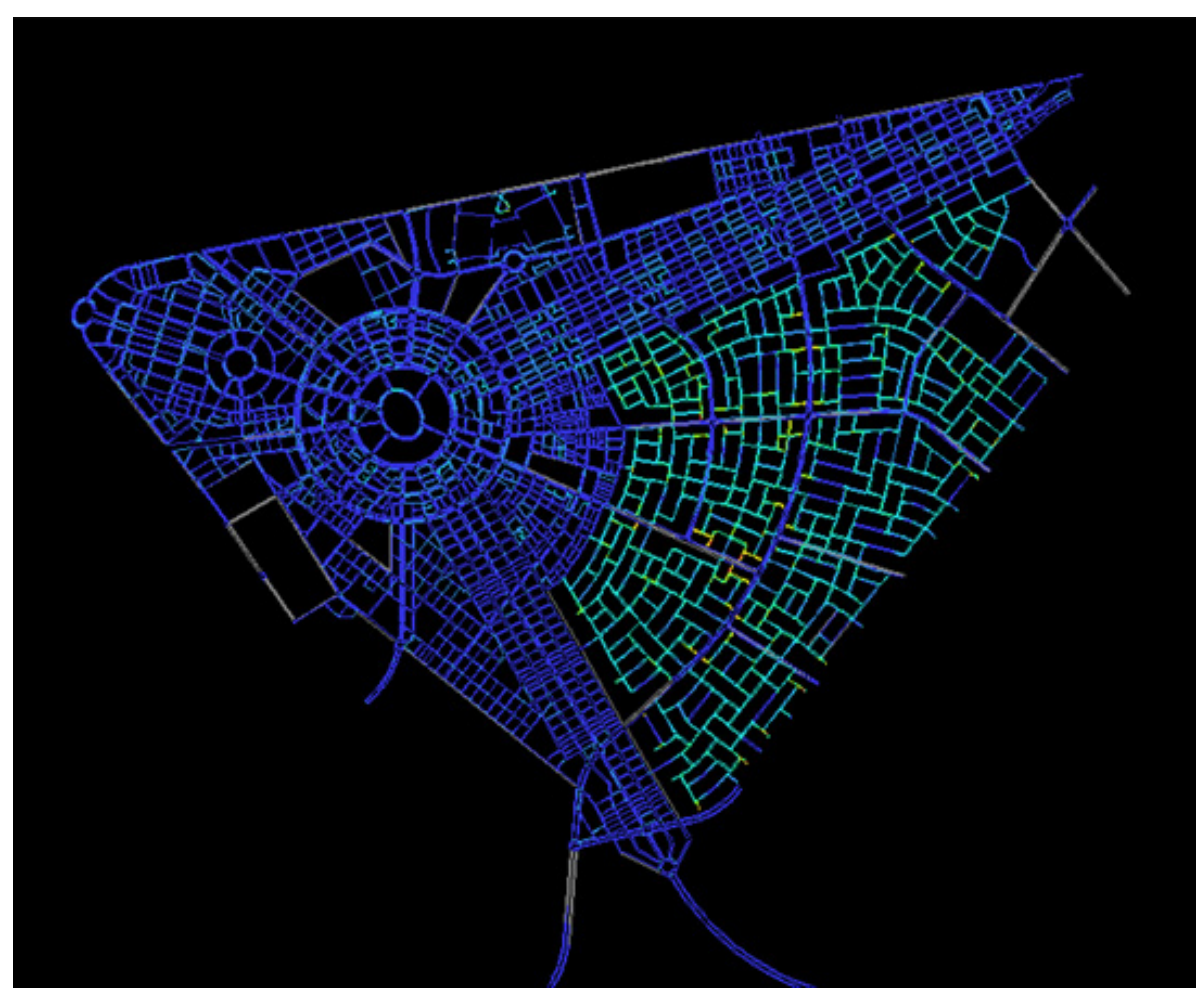

Fig. 7 Total depth—segment length weight—R200 (5 min walk).

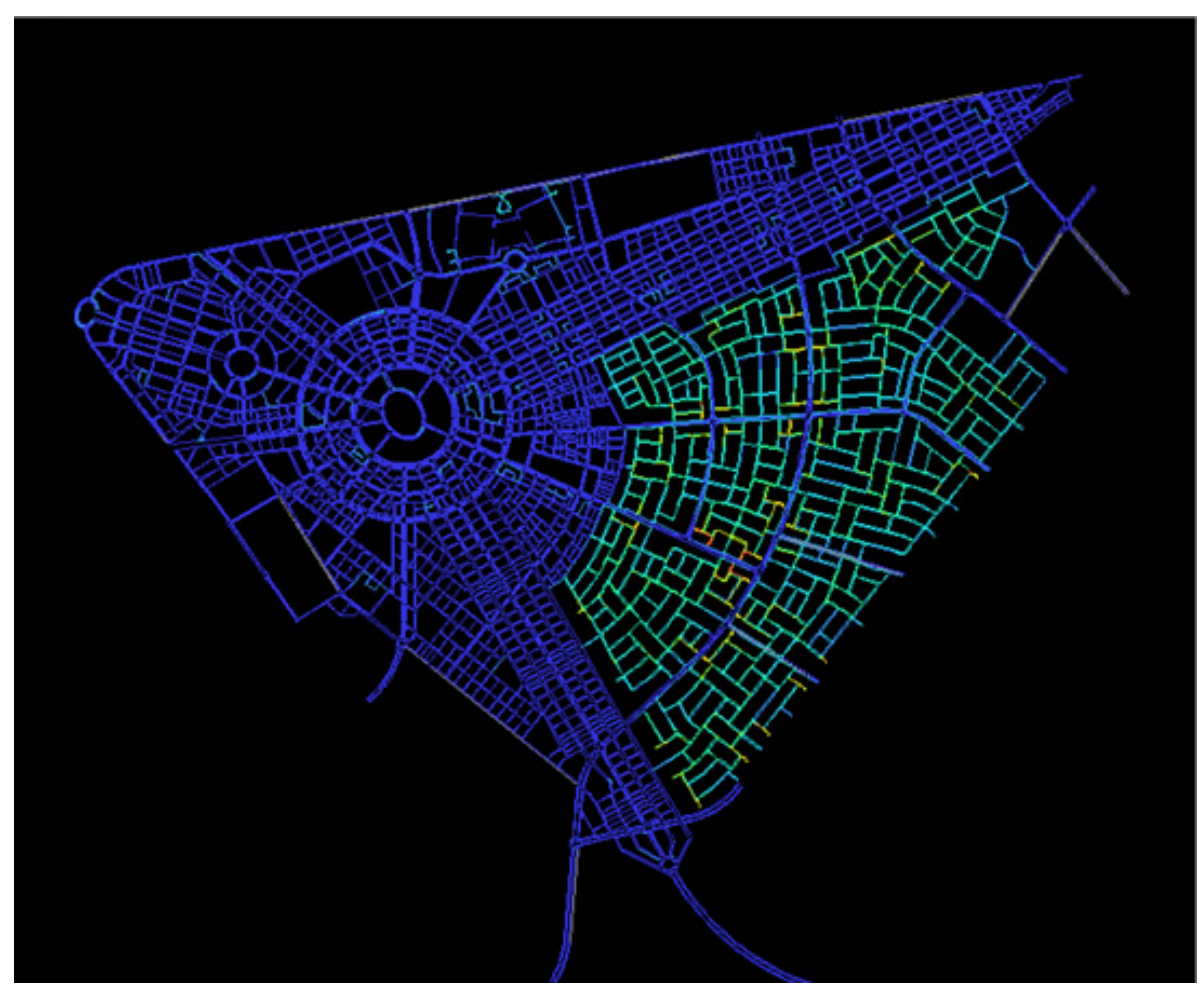

Fig. 8 Total depth—segment length weight-R400 (10 min walk). 


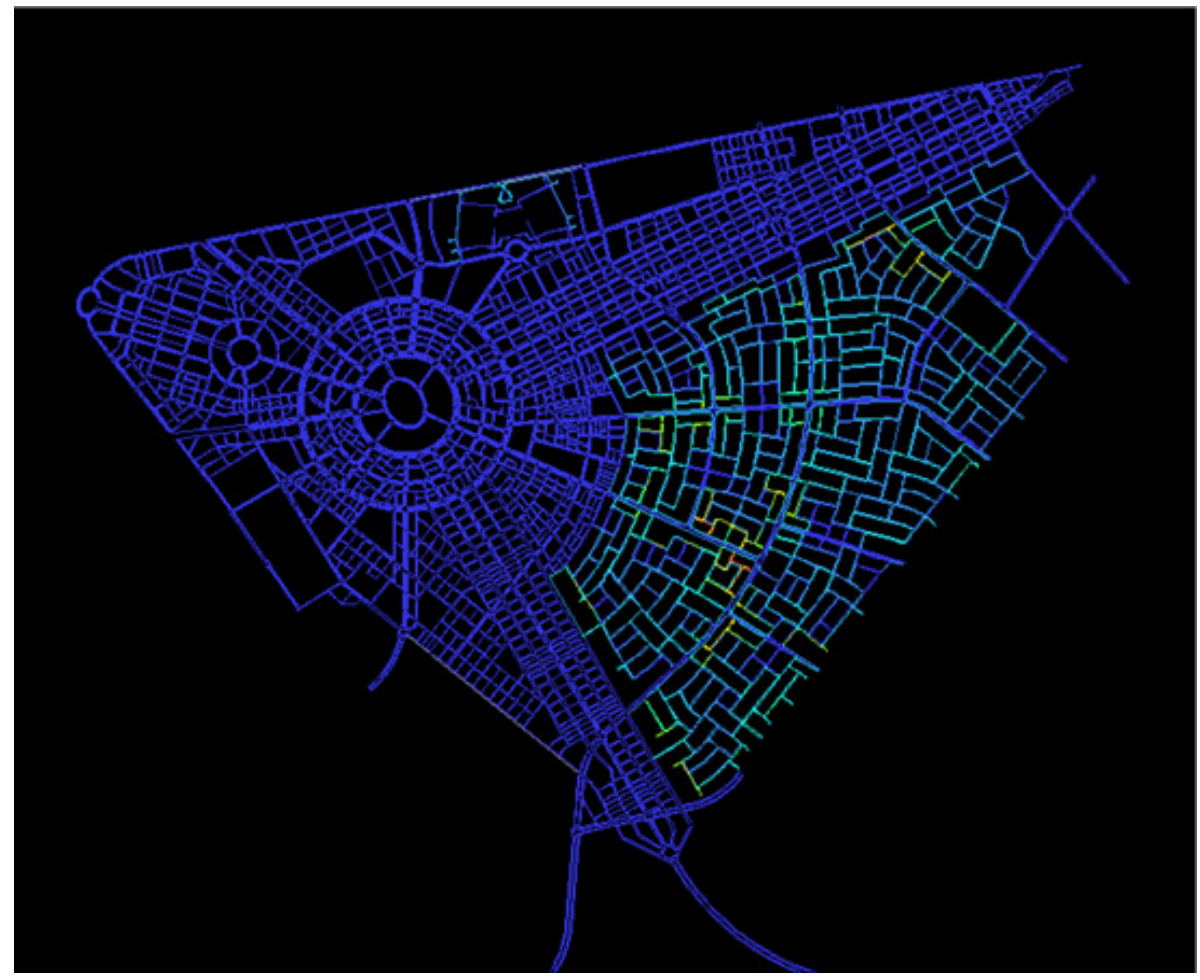

Fig. 9 Total depth—segment length weight-R800 (15 min walk).

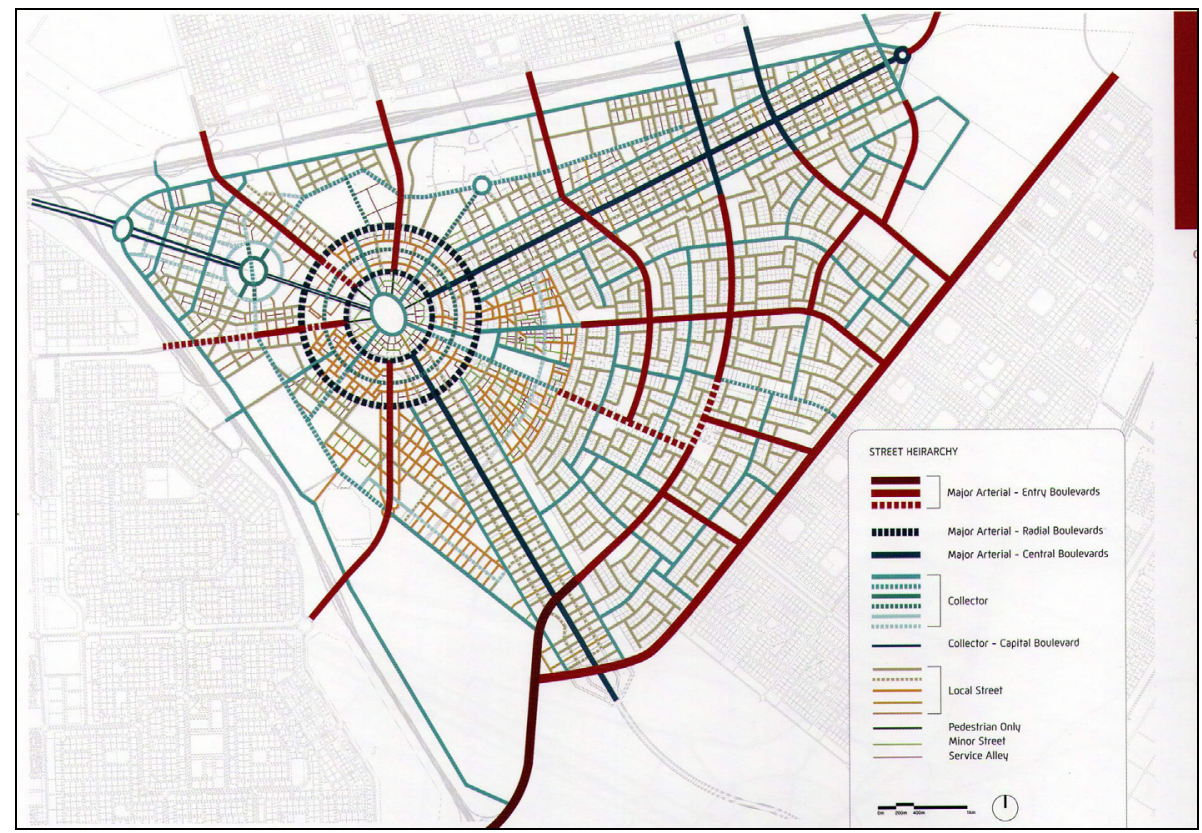

Fig. 10 Street hierarchy of the Capital District.

Source: The Abu Dhabi Urban Planning Council, 2007.

As explained in the methodology section, a comparison of the total depth graphs produced for the radii of $200 \mathrm{~m}, 400 \mathrm{~m}$ and $800 \mathrm{~m}$ was carried out with the land use, the streets hierarchy and the walking and cycling maps of the Capital District to verify the integration of the different segments to the whole system and the accessibility of different open spaces and buildings within optimum walking distances. 


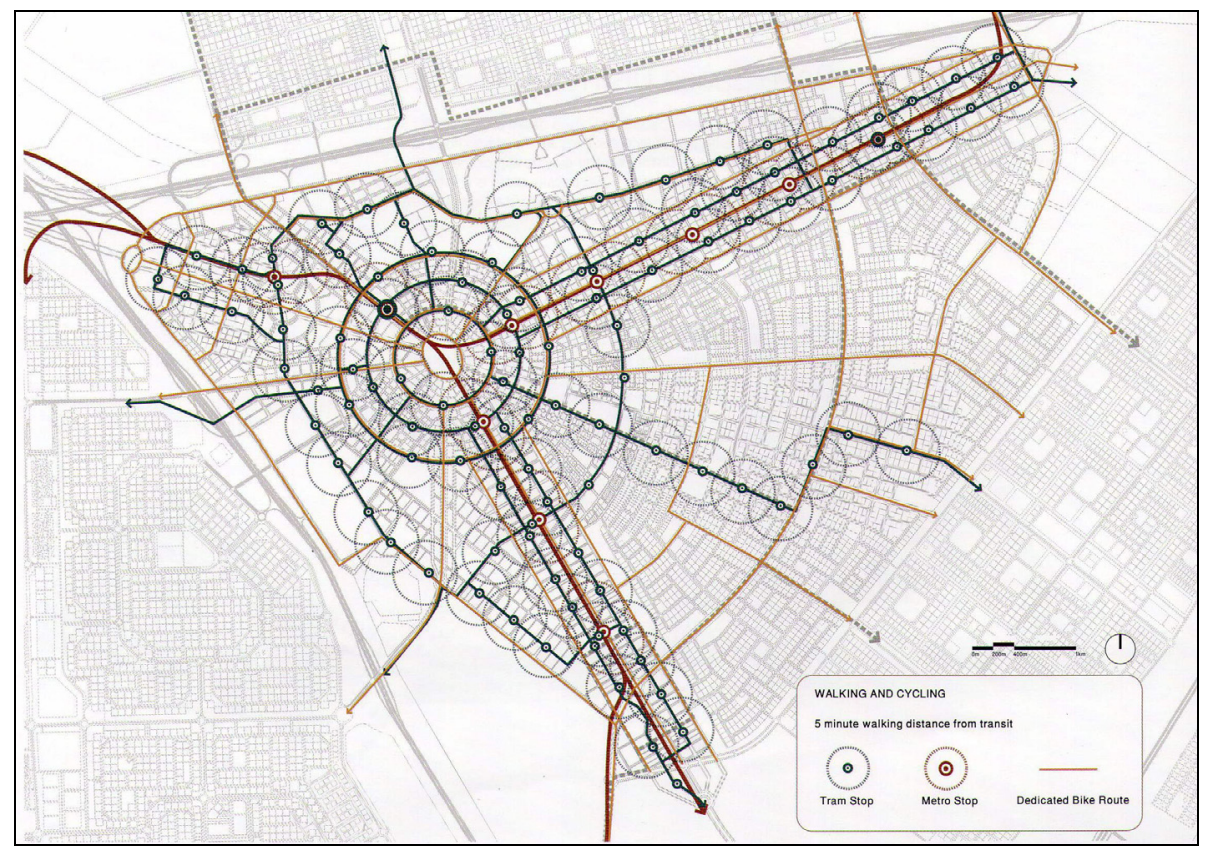

Fig. 11 Walking and cycling map of the Capital District.

Source: Abu Dhabi Planning Council, 2007.

The results of the comparison reveal the following:

- Fig. 7 that represents the total depth graph generated for the Capital District area indicates that a large number of shortest paths are connected to both collectors and local streets in the Emirati neighborhood, more than the major arterial, since they are represented in the red color reflecting higher values;

- The segments in the total depth graphs with a $200 \mathrm{~m}, 400 \mathrm{~m}$ and $800 \mathrm{~m}$ radii (Figs. 7-9) that overlay with the cycling routes and the major bus routes have less total depth values (blue color); which means that only a small number of shortest angular paths are connected to them within the walking distances mentioned above. Hence, they are less accessible, which affects the accessibility of the building or open spaces aligned to them or located near them;

- Beside the dominant residential use of the Emirati neighborhood, retail, religious, open space/recreational, health care and schools are planned to cover the whole area. However, their locations are not always near to the public transportation stops, which encourage the use of the car and discourage walkability under the hot climate of the UAE.
Furthermore, the cultural issue that bicycle riding by women is not popular in the region will not promote cycling amongst the female population;

- The location of tram and metro stops along one major arterial entry boulevard and one collector inside the Emirati neighborhood would generate long distances to walk by pedestrians between the stops and such destinations as work places, shops, or recreational areas. In addition, those dedicated bicycle routes connected to collectors and collector-capital boulevards and to the major arterial-entry, radial and central boulevards have a low value of total depth.

This discourages people who would like to travel to the Emirati neighborhood by public transportation and then use bicycles from the metro, bus or tram stops to reach their destinations, because the distance to cycle becomes longer, since these stops do not cover the whole area as mentioned above. Once again this would promote the use of cars as a main transportation means and discourage the use of the multi-transport model, or the transit oriented model which has demonstrated considerable success in other countries in the matter of sustainability

Finally, it is important to consider the Emirati 
neighborhood projected daytime population of more than 100,000 people that will be entering, moving within and exiting; more than 60,000 of these will be residents of the neighborhood precinct of the Capital District [9].

Assuming no limitation due to economic or physical factors, the author is recommending the following:

- Reconsider and extend the existing public transportation routes to cover the whole of any area wherever facilities like schools, retail and health care buildings are located;

- Encourage the combining of different public transportation means and create more metro and tram stops close to facilities at an optimum walking or cycling distance of $5 \mathrm{~min}$ to $10 \mathrm{~min}$.

\section{Conclusions}

The aim of this research was to study the accessibility and integration of streets, open spaces, public buildings and facilities in the whole urban system proposed in the Abu Dhabi 2030 Master Plan. The objective is to verify if the planned land uses and their locations, as well as the location of the public transportation stops afford an optimum walking distance to pedestrians under the heat. In addition to checking if the proposed plans are in compliance with the 2030 vision of Abu Dhabi and the creation of a sustainable community and a livable city that encourages walkability and cycling. These two factors alone if successfully incorporated will promote people's health, the use of open spaces, improve the integration of different ethnic groups within society and enhance socialization and interaction among the residents. Perhaps even more importantly, they will decrease the dependency on the car, resulting in reduced air pollution, traffic congestion and fuel consumption.

For this purpose, a detailed analysis at a smaller scale was carried out for the Emirati neighborhood of the Capital District, and total segment analysis was conducted by Depthmap software that applies space syntax theory. In order to check if the location of open spaces, facilities and public buildings are well located so as to be accessible on foot, total depth graphs were produced for different radii that correspond to walking distances and compared with the land use map, the roads hierarchy and walking and cycling roads proposed in the 2030 Master Plan.

The results showed that from among the total daytime population of 100,000 , some 40,000 daytime visitors who are not residents of the neighborhood would, if they chose to walk, be subject to long journeys from the tram, bus or metro stations to their destinations. Unfortunately due to the long distances between these stops and the different facilities and open space locations, and the hard climate of the country, this would not encourage walkability or cycling, and instead would encourage the use of the car.

The author recommended the expansion of the public transportation network to cover the whole neighborhood; effectively combine different means of transportation, and encourage the transit-oriented model for future development.

This research is part of a bigger project that aims to propose guidelines, by using simulation and modeling in the planning phase in order to combine the visibility of landmarks, open spaces, etc., and their accessibility on foot, to contribute to the creation of a microclimate through the arrangement of buildings at the urban scale; such arrangements should help walkability and maximize the use of open spaces and the voids between buildings to enhance interaction and sociability among the community members. Further work would cover the whole Capital District.

\section{References}

[1] Penn, A. 2001. "Space Syntax and Spatial Cognition-or, Why the Axial line?" Presented at the 3rd International Space Syntax Symposium, Atlanta, USA.

[2] Hillier, B. 2005. "The Art of Place and The Science of Space." World Architecture, special issue on space syntax, 96-102. 
[3] Hillier, B., 1999. "The hidden geometry of deformed grids: or, why space syntax works, when it looks as though it shouldn't." Environment and Planning B: Planning and Design, 26(2), pp.169-191.

[4] Alasdair, T. 2001. "Angular Analysis." Presented at the 3rd International Space Syntax Symposium, Atlanta, USA.

[5] Meziani, R., and Kaneda, T. 2007. "Toward Further Application of Visibility Analysis in the Case of Ghardaia." Presented at the 10th International Conference on: Computers in Urban Planning and Urban Management (CUPUM), Iguassu falls, Brazil.

[6] Meziani, R. 2012. "Visibility Analysis of the Capital District in the 2030 Master Plan of Abu Dhabi." Presented at the 17th International Conference on Urban Planning and Regional Development in the Information Society-GeoMultimedia, Schwechat, Netherlands.

[7] About.com. n.d. "Geography of United Arab Emirates."
Accessed February 2017. http://geography.about.com/library/cia/blcuae.htm.

[8] Abu Dhabi Urban Planning Council. 2007. Plan Abu Dhabi 2030-Urban Structure Framework Plan. Abu Dhabi, UAE.

[9] Abu Dhabi Urban Planning Council. 2017. Capital District. Abu Dhabi 2030 Vision. Abu Dhabi, UAE.

[10] Wikipedia. n.d. "Geography of the United Arab Emirates.” Accessed February 14, 2017. https://en.wikipedia.org/wiki/Geography_of_the_United_ Arab_Emirates.

[11] Alasdair, T. 2004. Depthmap: A Researcher's Handbook. London: Bartlett School of Graduate Studies, UCL.

[12] Desyllas, J., and Duxbury, E. 2001. "Axial Maps and Visibility Graph Analysis: A Comparison of Their Methodology and Use in Models of Urban Pedestrian Movement." Presented at the 3rd International Space Syntax Symposium, Atlanta, USA. 